\title{
A history of the Jannetta procedure
}

\author{
Anthony M. Kaufmann, MD, MSc, FRCSC, ${ }^{1}$ and Angela V. Price, MD, FRCSC ${ }^{2}$ \\ ${ }^{1}$ Section of Neurosurgery, Department of Surgery, University of Manitoba, Health Sciences Centre, Winnipeg, Manitoba, Canada;
} and ${ }^{2}$ Department of Neurological Surgery, University of Texas Southwestern Medical Center, Dallas, Texas

\begin{abstract}
Peter Jannetta was a neurosurgery resident when he proposed the neurovascular compression theory. He built upon the astute observations of Dandy, Gardner, and others who, in the era before the operating microscope, had successfully ventured into the posterior fossa. In 1965, Jannetta performed cranial nerve microdissections for dental students and identified the trigeminal portio intermedia. He proposed that preservation of these sensory fibers may avoid complete facial numbness, and together with Robert Rand developed a subtemporal transtentorial approach for selective rhizotomy for trigeminal neuralgia (TN). Such rash surgery, using an operating microscope, was then forbidden at their University of California, Los Angeles center, so they collaborated with John Alksne to perform the first surgery at Harbor General Hospital. Upon visualizing the trigeminal nerve root, Jannetta was surprised to see a pulsating superior cerebellar artery compressing the nerve and said "That's the cause of the tic." He also hypothesized that alleviating the observed vascular cross-compression may be curative.
\end{abstract}

A few months later, while assessing a patient with hemifacial spasm, Jannetta had the epiphany that this was the same disease process as TN, but instead affecting the facial nerve. The patient consented to what would become Jannetta's first microvascular decompression procedure. The senior faculty members who had forbidden such surgery were away, so the supervising neurosurgeon, Paul Crandall, granted the approval to perform the surgery and assisted. Via a retromastoid approach with the patient in the sitting position and using the operating microscope, Jannetta identified and alleviated the culprit neurovascular compression, with a cure resulting.

Jannetta presented his neurovascular compression theory and operative findings to the neurosurgical patriarchy of the time. Elders of the field were generally not inclined to accept the bold speculations of an untested neurosurgeon, and were often determined to discredit the new "cure" of the old diseases. Over decades of refining his surgical technique, documenting the outcomes, and enduring the skepticism he often faced, Jannetta's theory and his microvascular decompression procedure withstood critical analysis and have become recognized as one the great discoveries and advances in neurosurgery and medicine.

https://thejns.org/doi/abs/10.3171/2018.10.JNS181983

KEYWORDS Peter Jannetta; microvascular decompression; trigeminal neuralgia; hemifacial spasm; microneurosurgery; neurovascular compression; history; pain

$\mathrm{M}$ ICROVASCULAR decompression (MVD) surgery has become accepted as potentially curative for trigeminal neuralgia (TN), hemifacial spasm (HFS), and glossopharyngeal neuralgia. The concept that normal vessels may cause these cranial nerve disorders by compressing the respective nerve roots had been introduced by Dandy and Gardner. Jannetta later expanded the concept of this neurovascular compression (NVC) theory and developed the surgical procedure to alleviate this culprit. For Jannetta, the challenges of this delicate surgery at the dawn of the microsurgical era were rivaled by those he faced from the neurosurgical community's resistance and reluctance to accept the young newcomer's theories and authenticity. Over decades of refining his surgical procedure, documenting the outcomes, and enduring the skepticism he often faced, the NVC theory and his Jannetta procedure

ABBREVIATIONS HFS = hemifacial spasm; MVD = microvascular decompression; NVC = neurovascular compression; SCA = superior cerebellar artery; $\mathrm{TN}=$ trigeminal neuralgia; UCLA = University of California, Los Angeles.

SUBMITTED July 9, 2018. ACCEPTED October 2, 2018.

INCLUDE WHEN CITING Published online February 1, 2019; DOI: 10.3171/2018.10.JNS181983. 
withstood critical analysis and have become recognized among the great discoveries and advances in neurosurgery and medicine.

\section{On the Shoulders of Giants}

Descriptions of TN date back to the 1st century AD, and the clinical features were thoroughly characterized by Locke, André, and Fothergill in the 17th and 18th centuries. ${ }^{44}$ Effective medical therapies for the episodic but agonizingly painful condition would not be introduced for another 200 years. The disease, also called tic douloureux or neuralgia epileptiforme, earned the label of "suicide disease."

Early operative procedures included a variety of neurectomy and neurolytic injection procedures that offered at least short-term pain relief. At the turn of the 20th century, Spiller and Frazier introduced their retrogasserian rhizotomy procedure achieved via an extradural, subtemporal approach. ${ }^{43}$ This proved more successful for long-term pain relief, although it was associated with a significant incidence of severe facial sensory loss, keratitis, temporal lobe retraction injury, and facial paresis due to injury at the geniculate ganglion. Neurosurgeons and their patients accepted these risks to gain relief from the unbearable pain condition, and the rhizotomy procedure became the standard neurosurgical intervention for treatment of TN.

Dandy, in the 1920s and 1930s, advocated for the retromastoid craniectomy approach to access and section the trigeminal nerve root. ${ }^{6} \mathrm{He}$ was among the first neurosurgeons to successfully venture into the posterior fossa and considered this a more direct route and associated with less blood loss. Dandy also identified the potential to preserve some facial sensation and mastication strength with a selective or partial sensory rhizotomy, recognizing topographic organization of the portio major and the distinct fibers of the portio minor and the "accessory sensory fibers."

Dandy amassed a comparatively vast experience in performing transection of the trigeminal nerve root for treatment of TN. In his 1934 publication "Concerning the cause of trigeminal neuralgia," he described the total or subtotal division of the trigeminal root in 215 cases. ${ }^{5}$ Without the aid of illumination and magnification afforded by an operating microscope, Dandy was able to identify compression on the trigeminal nerve root by a superior cerebellar artery (SCA) loop in $30.7 \%$ and the compression by a branch of the petrosal vein in $14 \%$ of cases. Dandy also acknowledged that other unrecognized compressive lesions may have existed but were not adequately visualized by the surgical exposure of the day. He did not differentiate between static compression and pulsatile compression, the unique susceptibility of the proximal portion of the nerve root in causation of tic douloureux, or extrapolate his observation to consider the potential role for mobilizing the culprit vessel away from the underlying nerve. Dandy did, however, achieve excellent outcomes with his retromastoid rhizotomy approach, avoiding many of the shortcomings of the middle fossa approach. Other surgeons of the era were not equally successful operating through the posterior fossa and generally avoided this operation. Dandy's astute obser- vations and important contributions to the understanding and treatment of TN were therefore largely overlooked or disregarded by the neurosurgical community of the time.

In 1951 Taarnhøj introduced another alternative procedure that was intended to decompress the trigeminal nerve root at the porus trigeminus, and published a report in 1954. ${ }^{45}$ Gardner and Miklos also adopted this approach and presented their results together with those of Taarnhøj in a 1959 paper "Response of trigeminal neuralgia to decompression of sensory root; discussion of cause of trigeminal neuralgia." 10 With the patient in the sitting position, still without the aid of a microscope, and via an extended subtemporal approach, the dura mater overlying the proximal gasserian ganglion was opened. The incision extended through the superior petrosal sinus in the tentorium for a distance of $1 \mathrm{~cm}$ posterior to the petrous apex, thereby opening the porus trigeminus and freeing the sensory root from this dural sleeve. Gardner and Miklos also described the concurrent "non-traumatic manipulation" of the sensory root that was "gently brushed with a cotton pledget and irrigated with Ringer's solution." They explained: "The critical part of the operation appears to be a neurolysis or manipulation of the sensory root at the point where it crosses the apex of the petrous bone." Shelden and colleagues also believed the success from these procedures was due to the traumatic manipulation of the trigeminal pathway, and they achieved similar good results with mild trauma applied to the nerve with a blunt instrument or dental roll. ${ }^{40,41}$

Gardner later extrapolated the "non-traumatic manipulation" approach to the treatment of HFS, a condition he considered analogous to TN. In his 1962 publication "Concerning the mechanism of trigeminal neuralgia and hemifacial spasm," Gardner reported a 1955-1961 series of suboccipital approaches that followed a failed middle fossa procedure in 18 cases for TN and 19 cases for HFS. ${ }^{8}$ Still in the era that predated neurosurgical use of the operative microscope, he found an artery loop "compressing and circling or transfixing the nerve" in 6 cases and 7 cases, respectively; approximately the same one-third of cases Dandy had noted for TN. Gardner treated these with interposition of a Gelfoam pad between the offending artery and nerve but continued to recommend "non-traumatic manipulation" neurolysis during these decompression surgeries.

\section{Serendipity and New Insights}

Peter Joseph Jannetta was born in Philadelphia in 1932. He became an outstanding student-athlete on the college swimming, lacrosse, and football teams, en route to his medical doctorate from the University of Pennsylvania in 1957. He continued there in a General Surgery residency, where one of his mentors, Brooke Roberts, described Jannetta as "not one to simply accept the common wisdom. In general, it's the younger ones in the profession who tend to have the open minds and the older generation who test them, and Peter certainly was tested." ${ }^{\prime 2}$ Jannetta was also granted a National Institutes of Health-sponsored neurophysiology research fellowship, in Professor Sol Erulkar's laboratory. There he gained proficiency with use of a bin- 
ocular microscope in experiments examining feline spinal cord projections of the vestibular system. ${ }^{7}$ This foreshadowed Jannetta's introduction to microneurosurgery in his neurosurgical residency at the University of California, Los Angeles (UCLA) from 1963 to 1966. There, his mentors Robert Rand and Theodure Kurze were early adopters of the operating microscope for neurosurgery. ${ }^{36}$

Jannetta's residency and early career also coincided with the dawn of major developments in the management of TN. Medical treatment with phenytoin was introduced in the 1950s and carbazapine in the 1960s. Rhizotomy procedures also became more refined and less invasive, with the introduction of radiofrequency, glycerol, balloon compression, and later radiosurgery techniques. These advances were extensions of well-established concepts and introduced by distinguished senior professors. ${ }^{24}$ Jannetta's work, conversely, would challenge both.

In the book titled Working in a Very Small Place: The Making of a Neurosurgeon, the author Shelton describes the three serendipitous events that came together in 19651966 to lead Jannetta to develop his understanding of NVC disorders. ${ }^{42}$ First, Rand had assigned Jannetta to prepare microdissections of the cranial nerves for first-year dental students in the spring of 1965. Jannetta noticed a tiny bundle of nerve fibers at the proximal trigeminal nerve root, intermediate between the portio major and minor, something he had not known or seen before (Fig. 1). He speculated that preservation of these fibers, carrying light touch sensation, could avoid facial anesthesia when performing a proximal rhizotomy for treatment of TN..$^{16,31}$ He discussed his findings with Rand, who recalled similar observations made decades before by Dandy. Jannetta reviewed that work and noted that Dandy had indeed identified and preserved these "accessory sensory fascicles" when sectioning portio major for treatment of TN, although this technique had not been embraced by the neurosurgical community.

In 1965, Jannetta and Rand developed a subtemporal transtentorial microsurgical procedure for the purpose of sectioning the portio major with preservation of portio minor and "portio intermedia" to treat TN. ${ }^{32}$ Jannetta had performed multiple cadaveric dissections to gain experience with the new technique, but was forbidden to undertake such a rash new operation at UCLA. Instead, the first patient to undergo this new procedure was under the care of fellow neurosurgeon John Alksne at the allied Harbor General Hospital in Los Angeles. He too had recognized the advantages of the operative microscope and was supportive of Jannetta's innovative ideas for treatment of TN. ${ }^{1}$ The patient was a 52-year-old man with a 10-year history of right-sided TN. He had been admitted with an acute flare-up, which was now refractory to the alcohol injections and medications that had provided temporary relief in preceding years. He was suffering approximately 200 pain attacks per day and gave consent to undergo a selective sensory rhizotomy.

The procedure was performed by Jannetta with Alksne assisting and Rand observing in February 1966. The operating microscope, personally purchased by Rand, had been driven from UCLA in Jannetta's 1957 Ford station wagon and reassembled at Harbor General Hospital for the surgery. Using the subtemporal approach, they exposed the

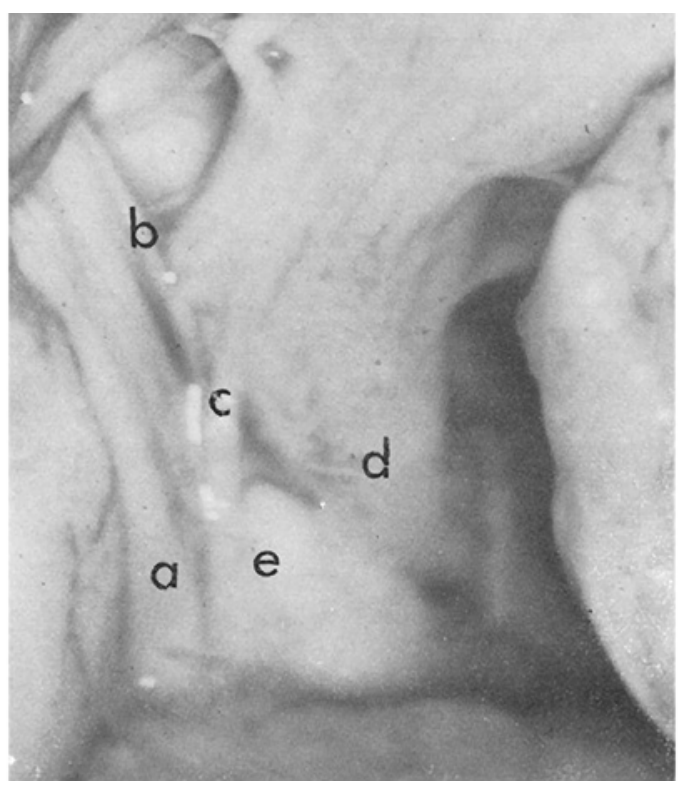

FIG. 1. While he was a neurosurgery resident in 1965, Jannetta was assigned to prosect cranial nerve specimens for teaching demonstrations to dental students. He identified sensory fiber bundles intermediate to the portio major and minor. This led him to develop a selective or partial trigeminal rhizotomy, which was intended to treat TN while preserving a degree of facial sensation. View through a dissecting microscope of the right trigeminal nerve at the pons: (a) motor branches; (b) intermediate fibers with motor branches. Note crossing fibers between motor and major sensory roots: (c) intermediate fibers leaving the portio major and entering the pons between motor and major sensory roots; (d) "fibrous cone" region of the portio major; (e) pons. Original magnification $\times 10$. Reprinted with permission from Jannetta PJ: Gross (mesoscopic) description of the human trigeminal nerve and ganglion. J Neurosurg $26(1$ Suppl):109-111, 1967.

trigeminal nerve through an opening of the tentorium cerebelli. Jannetta then noted a pulsating artery cross-compressing the nerve and said to Alksne "That's the cause of the tic." (Fig. 2). They proceeded with the planned sectioning of the portio major. Jannetta made similar observations in subsequent patients undergoing the same procedure for intractable TN. He also completed 56 cadaver dissections in subjects presumably not afflicted by $\mathrm{TN}$, and there found no evidence of similar trigeminal nerve compression by vessels at or near the pons. ${ }^{12}$ Jannetta was convinced that NVC was the cause of TN and hypothesized that mobilizing the culprit vessel away from the nerve could potentially cure the disease, although he had no opportunity to test his theory.

The third serendipitous event occurred while Jannetta was seeing patients in the neurosurgery clinic in May 1966. He described a 41-year-old precision mechanic approaching down the hallway with severe left-sided HFS. Jannetta then had an epiphany as he recognized that this was another cranial nerve hyperactivity condition analogous to $\mathrm{TN}$ and extrapolated his observations on $\mathrm{TN}$ to theorize that HFS was similarly caused by vascular compression of the facial nerve. He believed that the condition could also be cured by mobilizing the culprit vessel away from the affected nerve. The patient had been unable to work due to the uncontrollable forceful eye closures and was seek- 


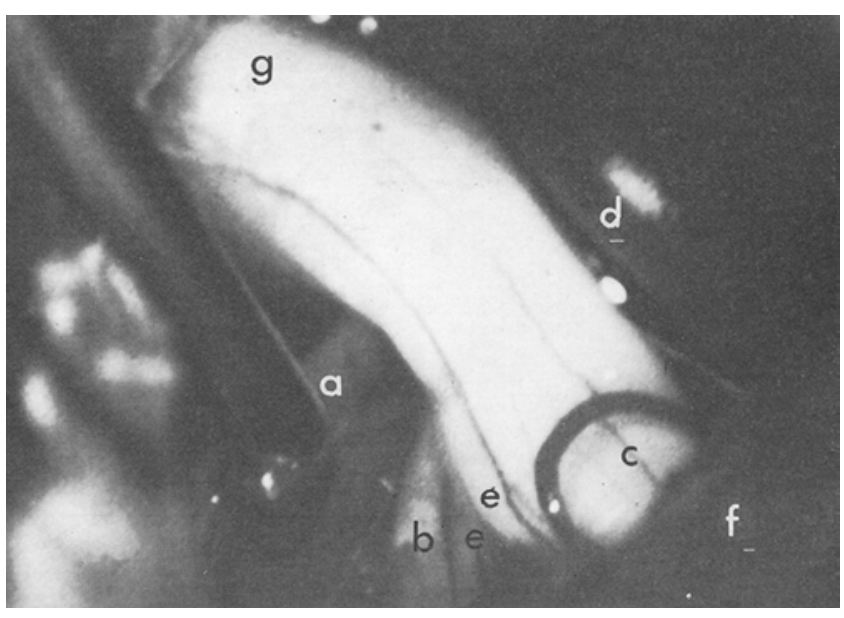

FIG. 2. The first of Jannetta's selective trigeminal rhizotomy operations for TN was performed with Alksne and observed by Rand. Upon exposing the nerve root via a transtentorial approach, Jannetta was surprised to see arterial distortion of the nerve root at the pons. He immediately believed "That's the cause of the tic." View of the right trigeminal nerve at the pons through a dissecting microscope. Transtentorial approach to the nerve from a superolateral direction: (a) small tortuous branches of the SCA compressing nerve at pons; (b) motor roots; (c) "fibrous cone" region of portio major; (d) another arterial branch; (e) intermediate fibers; (f) cerebellum (retracted); and (g) trigeminal nerve entering dural canal. Tortuous arterial branches are supported partly away from the nerve by the instrument. Original magnification $\times 16$. Reprinted with permission from Jannetta PJ: Arterial compression of the trigeminal nerve at the pons in patients with trigeminal neuralgia. J Neurosurg 26:159-162, 1967.

ing neurosurgical treatment. Jannetta explained the thenstandard option to mechanically injure the facial nerve through a posterior fossa approach. He also explained his own NVC theory and proposed that an atraumatic decompression of the nerve could potentially not only avoid facial weakness but cure the otherwise intractable disease. The patient consented to what would become Jannetta's first MVD procedure.

The operation was performed on June 2, 1966, at UCLA. Coincidently and again serendipitously, the senior faculty members who had forbidden such surgery were away. The supervising neurosurgeon, Paul Crandall, agreed to allow Jannetta to perform the proposed procedure. A retromastoid approach with the patient in the sitting position was used, as was the operating microscope. Jannetta found the anterior inferior cerebellar artery coursing around the distal facial nerve but was not convinced that this artery was the cause of the HFS. He explored further toward the brainstem and identified a vein along the pons that was compressing and distorting the facial nerve. ${ }^{22} \mathrm{He}$ then coagulated and sectioned the vein, such that the freed facial nerve sprang into a relaxed course. The patient recovered well, and spasms ceased the following day, not to return. It was rare that the HFS in that first case was due to a vein, although it was a great testament to Jannetta's insight and skill to recognize the presumed culprit and safely alleviate the compression. One can only wonder if not for Jannetta's pioneering efforts whether any other neurosurgeon would have ever ventured to test the NVC theory, or what the future of this surgery would have been if the first operation had not been successful.
A couple of months after Jannetta's first MVD for HFS, he and Rand performed the first MVD for TN. The 54-year-old woman was a private patient of Rand's, who had consented for their transtentorial selective rhizotomy. The procedure was performed on August 4, 1966, and as in prior cases, vascular compression on the trigeminal nerve root became evident. This time, Rand obtained additional intraoperative consent from the patient's husband to change the original plan and instead they performed a vascular decompression. The culprit SCA was mobilized away from the root and a small piece of Ivalon sponge was inserted to maintain the separation. The surgery was successful and the patient enjoyed permanent pain relief. ${ }^{34}$ Over subsequent decades, Jannetta went on to refine his NVC concept and the MVD procedure, as now performed worldwide. Although he always recognized and credited the related contributions of his neurosurgical predecessors, Jannetta's concept development was his own, as was his singular success in bringing MVD into the mainstream of modern neurosurgical practice.

\section{Introducing the Jannetta Procedure to the Neurosurgical Community}

Jannetta, still a neurosurgical resident at the time, participated in a workshop titled "Structural Mechanisms of Trigeminal Neuralgia."12 He described his initial findings of NVC in 5 cases of TN, and hypothesized: "this minor arterial distortion of the trigeminal nerve at the pons may be a contributing factor in trigeminal neuralgia." $12 \mathrm{He}$ further proposed that surgical decompression of the vascular culprit may provide the means to cure the condition: "This possible definitive procedure, namely, release of the artery without nerve section, is planned in a future series of patients." Jannetta shared the lecture with senior neurosurgeons who presented alternative theories and approaches, considered more acceptable at the time.

Later that same year at the 1967 Congress of Neurological Surgeons' annual meeting in San Francisco, Jannetta and Rand presented their experience with use of the operating microscope.${ }^{35}$ Coincidentally, James Gardner was that year's honored guest and opined that TN was caused by a compression of the nerve, usually by an artery or petrous apex bone, leading to demyelination and short-circuiting of the neural transmissions. ${ }^{9}$ Gardner also described the similarities between TN and HFS in his address, and continued to recommend surgical treatment with "nontraumatic manipulation" of the nerve by instruments and "forceful stream of Ringer solution" sufficient to produce swelling of the nerve, even when a vessel was found to be compressing the nerve. It was instead Jannetta, just having completed his neurosurgery residency, who pursued the concept that TN and HFS were primarily caused by NVC that could be safely and effectively cured by an operation to mobilize the culprit vessel away from the affected nerve root entry/exit zone.

Directly after completing his residency, Jannetta was named associate professor and chairman of the Section of Neurological Surgery, Department of Surgery, at Louisiana State University Medical Center. He had already performed 9 transtentorial approaches to section the tri- 


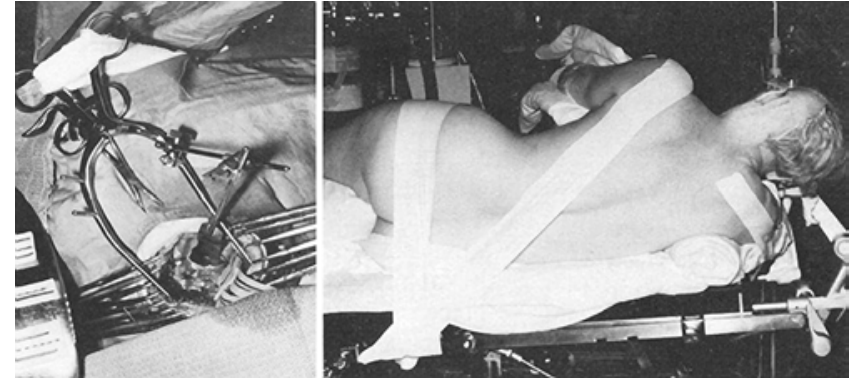

FIG. 3. Jannetta abandoned the subtemporal transtentorial approach for TN, as well as the sitting position for HFS. Instead, like Dandy decades before, he adopted a lateral position and retromastoid craniectomy to access the cranial nerves of the posterior fossa. Reprinted with permission from Jannetta PJ, Abbasy M, Maroon JC, Ramos FM, Albin MS: Etiology and definitive microsurgical treatment of hemifacial spasm. Operative techniques and results in 47 patients. J Neuorsurg 47:321-328, 1977.

geminal nerve root with Rand; they found vascular crosscompression evident in 8 cases and an undiagnosed meningioma in 1 case. ${ }^{28}$ In a subsequent small series, without the expert assistance of Rand, temporal lobe injury led to seizures in 2 patients. Jannetta also recognized that the transtentorial approach was not well suited to mobilize vessels away from the trigeminal nerve. He acknowledged these issues in a published letter in which he cautioned the rare neurosurgeon who had adopted his original technique and promised improvements: "A new approach has been devised which so far appears to be more suitable for safe, definitive treatment of tic douloureux in the hands of a trained microneurosurgeon."14

Jannetta abandoned the transtentorial procedure in favor of access through a suboccipital craniectomy while in New Orleans, where he was freed from the restrictions against using this approach. ${ }^{30} \mathrm{He}$ thereafter continued developing his surgical procedure in Pittsburgh, where he was appointed professor and director of the Division of Neurological Surgery at the University of Pittsburgh Medical Center in 1971, and later chairman of the newly formed Department of Neurological Surgery. Jannetta published his first series of MVD procedures in 1970, consisting of 8 HFS cases, including the 4-year follow-up of the first successful case.22 A larger HFS series followed in 1975 with a bold but justified title: "The cause of hemifacial spasm: definitive microsurgical treatment at the brainstem in 31 patients." 13

Jannetta was simultaneously expanding his experience with MVD for TN. Having adopted the retrosigmoid approach, he also transitioned from the traditional sitting position to a horizontal "lounging" position before finally settling on the same lateral decubitus position originally described by Dandy (Fig. 3). ${ }^{29}$ In a 1974 letter published in the Journal of the American Medical Association, Jannetta described his 8-year experience with 150 cases of tic, usually caused by vascular compression and alleviated with "microneurosurgery," 26 and this was followed by complete manuscripts published in $1976^{21}$ and $1977 .{ }^{23}$ At the 24th Congress of Neurological Surgeons in 1976, Jannetta presented his decade-long experience with "Treatment of trigeminal neuralgia by suboccipital and transtentorial
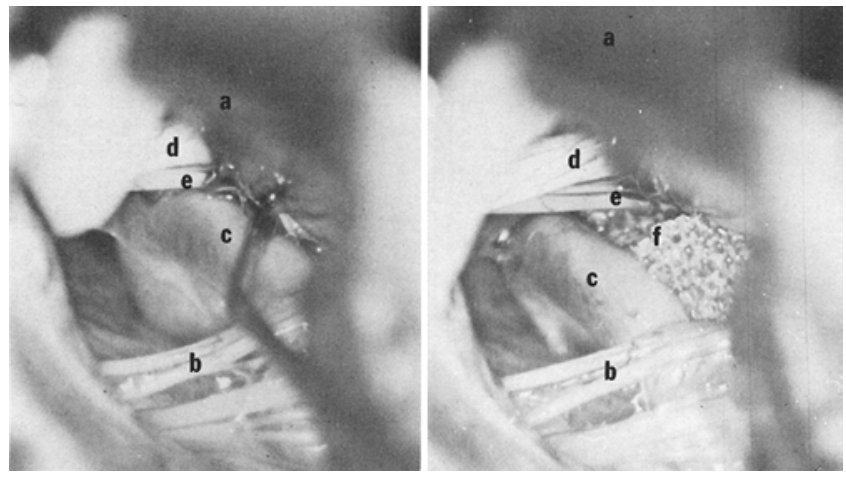

FIG. 4. Jannetta began to amass an extensive experience with MVD surgeries for HFS and TN, leading to a growing list of publications where he explained the techniques and results. Views of exposure of the lower cranial nerves in hemifacial spasm caused by a loop of the vertebral artery. Left retromastoid craniectomy. Retractor on cerebellum (a); ninth and tenth cranial nerves (b); vertebral artery (c); eighth cranial nerve (d); seventh cranial nerve (e); and prosthesis in place (f). Original magnification $\times 16$. Reprinted with permission from Jannetta PJ, Abbasy M, Maroon JC, Ramos FM, Albin MS: Etiology and definitive microsurgical treatment of hemifacial spasm. Operative techniques and results in 47 patients. J Neuorsurg 47:321-328, 1977.

cranial operations." ${ }^{28}$ His conclusion was succinct: "Trigeminal neuralgia is a symptom due to an abnormality at the root entry zone of the trigeminal nerve at the pons. It is due to vascular cross-compression in most cases" and the "pain can be relieved by vascular decompression without loss of neural function." He emphasized the importance to thoroughly mobilize or transpose the culprit vessel away from the affected nerve root: "It is most important that as an artery loop is separated, its axis is changed, and the sponge placed, that the artery not be kinked proximally or distally. The arachnoid opening may be extended to allow a smooth curve of the vessel." This nontraumatic, novel surgical technique was a major shift from the standard destructive operative treatments that then predominated, including radiofrequency, glycerol, balloon compression, and peripheral rhizotomies.

Jannetta meticulously cataloged his surgical observations and outcomes (Fig. 4). The completion of each case was followed by an entry into the MVD logbook, complete with demographic data and diagrams. He was also unreserved and forthright in documenting his surgical failures and complications. In an address to the 26th Congress of Neurological Surgeons in 1978, titled "Microsurgery of cranial nerve cross-compression," Jannetta candidly presented severe operative morbidities, mortalities, and decision errors that were less rare at the infancy of the microneurosurgical era. ${ }^{20}$ Such professional honesty and integrity were natural to Jannetta, as was his continual effort to optimize patient outcomes. This led him to integrate other new technologies such as intraoperative monitoring during MVD surgery. ${ }^{11}$

Although Jannetta presented his ideas and results in a scientific, logical, and honest manner, the reception was at times hostile and affected the young neurosurgeon. His reply to critics and skeptics was polite and informative. ${ }^{4,17,18,25}$ It is, however, no exaggeration that Jannetta's theory and procedure upset his profession. As Shelton described, there 


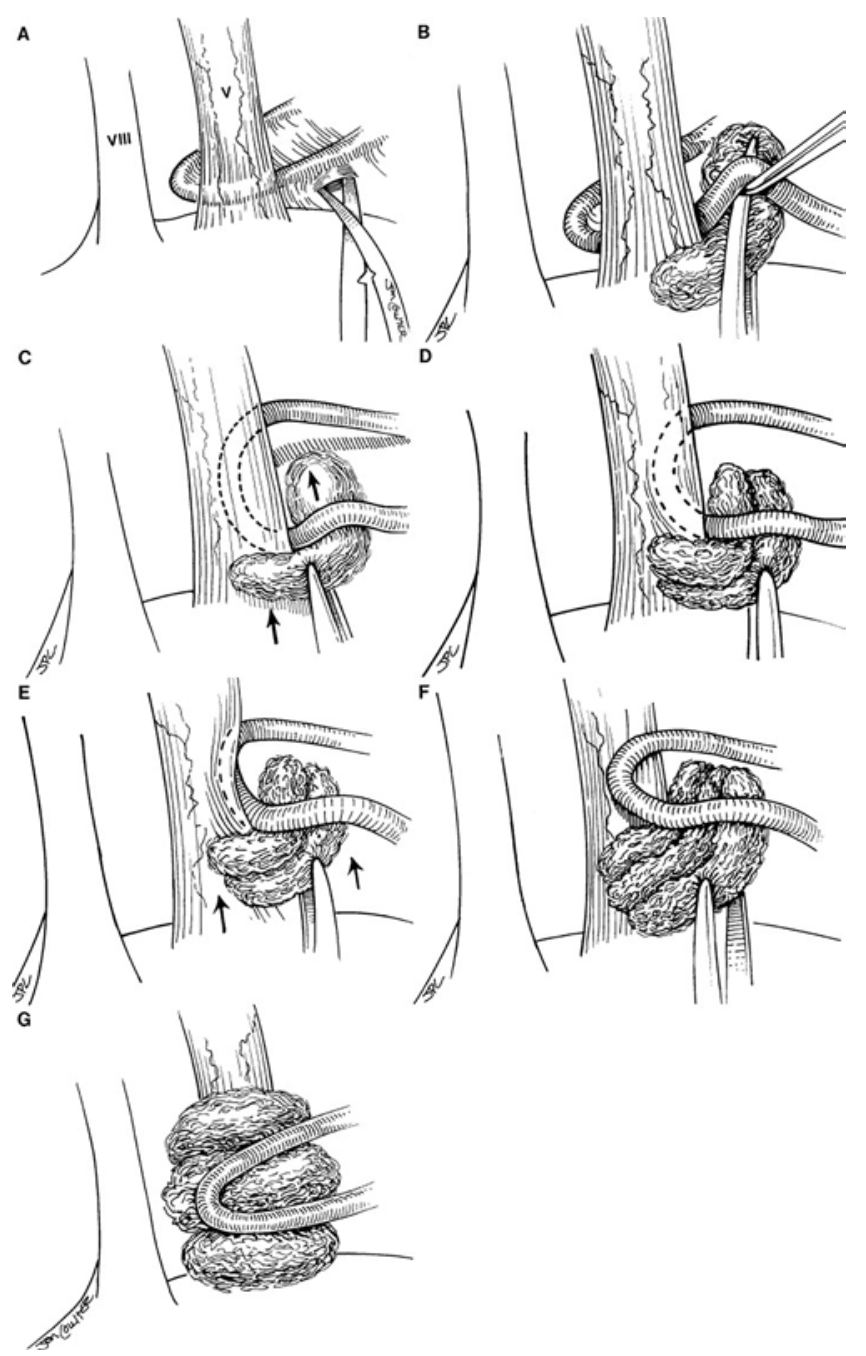

FIG. 5. Jannetta's insights gained over thousands of operations have been chronicled in hundreds of publications. His contributions have positively impacted patients around the world, whose neurosurgeons have embraced the lessons learned and shared by the pioneer of the Jannetta procedure (illustrated in panels A-G). Reprinted with permission from McLaughlin MR, Jannetta PJ, Clyde BL, Subach BR, Comey CH, Resnick DK: Microvascular decompression of cranial nerves: lessons learned after 4400 operations. J Neurosurg 90:1-8, 1999.

were several reasons for this, including Jannetta's young age, his junior rank, his use of the surgical microscope, the profession's resistance to new ideas, and, finally, Jannetta's own unawareness of these things. ${ }^{42}$ In Jannetta's textbook Trigeminal Neuralgia, Madjid Samii wrote kind words about his friend's accomplishments. ${ }^{38}$

I am extremely honored and pleased to write the foreword to this long-expected, and much needed, book. I congratulate my dear friend Peter Jannetta on this wonderful achievement and to express my deep admiration to his great achievements and his personality.

Samii continued to touch on the challenges Jannetta confronted while introducing his new ideas and affecting scientific change.

I will never forget my initial impressions when I first met Peter Jannetta at a neurosurgical meeting in the early seven- ties: there was a young man standing in front of auditory of neurosurgeons, among them several of the most respected and well-known, who, despite his very logical and convincing presentation, were unable - or unwilling - to understand or accept his ideas. I remember clearly the tears I saw in the eyes of Peter. Once created, revolutionary ideas need a man of big capacity, intellectual strength, and endurance that will put them into practice. Peter Jannetta was just that person.

Jannetta accepted the challenge of introducing the scientific and medical breakthrough. He appreciated the insights of Kuhn, a physicist, who wrote about how scientific communities react to change, and came to realize that the process was not unique to him or to neurosurgery. ${ }^{27}$

My lack of understanding of the process of acceptance was naive. But young and naive people see and do new things, partly because they do not understand that something cannot be done. In The Structure of Scientific Revolutions, Thomas Kuhn clearly organized the sequence of thoughts in the trials and assumption of new ideas. He was the first to describe the paradigm shift, and he clarified the sequence elegantly. His book should be read by anyone doing new work in science or medicine. It generally takes 20 years or more for a new paradigm to be developed and accepted. This time lag occurs as we wait for the old guard, to whom the new ideas are anathema, to retire or die. The younger generation accepts the new paradigm as more profound and acceptable than the old system of thought. But the better the new idea, the longer it may take for acceptance.

Jannetta, alongside his expanding cohort of trainees and colleagues, went on to publish milestone articles demonstrating the efficacy and safety of the MVD procedure (Fig. 5). The general medical community was introduced to the bold conclusion only in 1996, when the long-term results of MVD for TN gained acceptance for publication in the New England Journal of Medicine. ${ }^{2}$ Similar definitive papers were published for HFS, ${ }^{3}$ glossopharyngeal neuralgia,${ }^{37}$ and the MVD technique ${ }^{33}$ while Jannetta continued to explore the potential implications of vascular cross-compression in other disorders of the cranial nerves and brainstem. ${ }^{15,19}$

Those privileged to know Peter Jannetta saw him as accomplished, generous, and charismatic (Fig. 6). ${ }^{39} \mathrm{He}$ said that once he began to practice medicine he never worked another day in his life; that was how he experienced the honor to serve in medicine. His passion was for helping others; his patients, colleagues, and those he mentored. These traits garnered him many honors and accolades. One of the most meaningful to Jannetta was his 1990 induction to the Horatio Alger Association of Distinguished Americans, "dedicated to the simple but powerful belief that hard work, honesty and determination can conquer all obstacles."

\section{Conclusions}

Jannetta was not the first to describe the occurrence of NVC in TN or HFS, nor to hypothesize that these compressions were a cause of TN, HFS, and other cranial nerve disorders. He was, however, able to make these observations and develop his procedure independently. $\mathrm{He}$ persevered through attacks upon his character and integrity that sometimes became personal, but came to accept these challenges in his role as innovator and educator. 


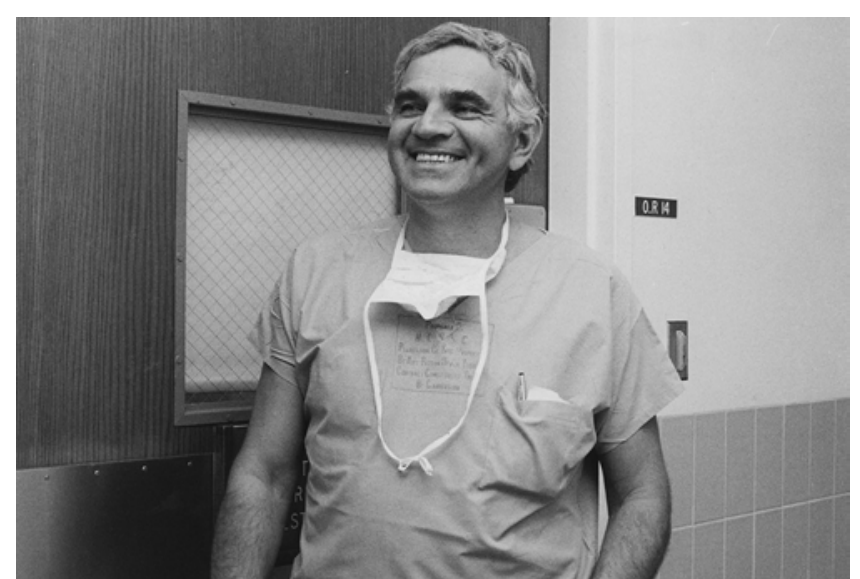

FIG. 6. Jannetta was surprised at the resistance and opposition he encountered when presenting his NVC concept and its surgical treatment. He accepted and overcame these challenges, while maintaining a generous character and passion for helping others. Copyright Raymond F. Sekula Jr. Published with permission from World Neurosurgery (http:// dx.doi.org/10.1016/j.wneu.2016.06.068).

Patients from around the world came seeking consultation with Jannetta, as did local residents of his adopted hometown of Pittsburgh. He treated them all with equal compassion and respect. His charisma was legendary, balanced with a humility and earnest desire to help. To each of his patients he promised to do his best, and that was usually the happy beginning of the rest of their lives cured of a devilish disease. To those for whom he had no treatment to offer, he promised to contact them if ever new approaches became available. Indeed, he maintained a list of his patients with "facial pain of obscure origin" in hopes of someday finding a solution.

Over decades of refining his surgical technique, documenting the outcomes, and enduring the skepticism he often faced, the NVC theory and his Jannetta procedure withstood critical analysis and have become recognized as one the great discoveries and advances in neurosurgery and medicine.

\section{Acknowledgments}

We are grateful to Ms. Kim Chell for her assistance in preparation of this manuscript.

\section{References}

1. Alksne JF: Microsurgical vascular decompression of cranial nerves. Am J Surg 140:156-157, 1980

2. Barker FG II, Jannetta PJ, Bissonette DJ, Larkins MV, Jho HD: The long-term outcome of microvascular decompression for trigeminal neuralgia. N Engl J Med 334:1077-1083, 1996

3. Barker FG II, Jannetta PJ, Bissonette DJ, Shields PT, Larkins MV, Jho HD: Microvascular decompression for hemifacial spasm. J Neurosurg 82:201-210, 1995

4. Beatty RA: Hemifacial spasm. J Neurosurg 48:317-318, 1978 (Letter)

5. Dandy WE: Concerning the case of trigeminal neuralgia. Am J Surg 24:447-455, 1934

6. Dandy WE: Operation for the cure of tic douloureux; partial section of the sensory root at the pons. Arch Surg 18:687734,1929
7. Erulkar SD, Sprague JM, Whitsel BL, Dogan S, Jannetta PJ: Organization of the vestibular projection to the spinal cord of the cat. J Neurophysiol 29:626-664, 1966

8. Gardner WJ: Concerning the mechanism of trigeminal neuralgia and hemifacial spasm. J Neurosurg 19:947-958, 1962

9. Gardner WJ: Trigeminal neuralgia. Clin Neurosurg 15:1-56, 1968

10. Gardner WJ, Miklos MV: Response of trigeminal neuralgia to decompression of sensory root; discussion of cause of trigeminal neuralgia. J Am Med Assoc 170:1773-1776, 1959

11. Grundy BL, Jannetta PJ, Procopio PT, Lina A, Boston JR, Doyle E: Intraoperative monitoring of brain-stem auditory evoked potentials. J Neurosurg 57:674-681, 1982

12. Jannetta PJ: Arterial compression of the trigeminal nerve at the pons in patients with trigeminal neuralgia. J Neurosurg 26:159-162, 1967

13. Jannetta PJ: The cause of hemifacial spasm: definitive microsurgical treatment at the brainstem in 31 patients. Trans Sect Otolaryngol Am Acad Ophthalmol Otolaryngol 80:319322,1975

14. Jannetta PJ: Complications from microsurgical treatment of tic douloureux. J Neurosurg 40:675, 1974 (Letter)

15. Jannetta PJ: Cranial nerve vascular compression syndromes (other than tic douloureux and hemifacial spasm). Clin Neurosurg 28:445-456, 1981

16. Jannetta PJ: Gross (mesoscopic) description of the human trigeminal nerve and ganglion. J Neurosurg 26 (1 Suppl):109-111, 1967

17. Jannetta PJ: Hemifacial spasm resolution without vascular decompression. Neurosurgery 20:63, 1987 (Letter)

18. Jannetta PJ: Hemifacial spasm: treatment by posterior fossa surgery. J Neurol Neurosurg Psychiatry 46:465-466, 1983

19. Jannetta PJ: The history of microvascular decompression surgery, in Li ST, Zhong J, Sekula RF Jr (eds): Microvascular Decompression Surgery. Dordrecht: Springer, 2016, pp 1-7

20. Jannetta PJ: Microsurgery of cranial nerve cross-compression. Clin Neurosurg 26:607-615, 1979

21. Jannetta PJ: Microsurgical approach to the trigeminal nerve for tic douloureux, in Krayenbühl H, Maspes PE, Sweet WH (eds): Pain - Its Neurosurgical Management. Part I: Procedures on Primary Afferent Neurons. Basel: Karger, 1976, Vol 7, pp 180-200

22. Jannetta PJ: Microsurgical exploration and decompression of the facial nerve in hemifacial spasm, in Skinner DB, Ebert PA (eds): Current Topics in Surgical Research. New York: Academic Press, 1970, Vol 2, pp 217-220

23. Jannetta PJ: Observations on the etiology of trigeminal neuralgia, hemifacial spasm, acoustic nerve dysfunction and glossopharyngeal neuralgia. Definitive microsurgical treatment and results in 117 patients. Neurochirurgia (Stuttg) 20:145-154, 1977

24. Jannetta PJ: Preface, in Jannetta PJ (ed): Trigeminal Neuralgia. New York: Oxford, 2011, pp ix-xi

25. Jannetta PJ: Rebuttal of commentaries concerning the focus article: Vascular compression is the cause of trigeminal neuralgia. APS J 2:237-238, 1993

26. Jannetta PJ: Tic douloureux and facial spasm. JAMA 228:1637-1638, 1974 (Letter)

27. Jannetta PJ: Treatment of patients with trigeminal neuralgia, in Al-Mefty O (ed): Controversies in Neurosurgery II. New York: Thieme, 2013, pp 350-352

28. Jannetta PJ: Treatment of trigeminal neuralgia by suboccipital and transtentorial cranial operations. Clin Neurosurg 24:538-549, 1977

29. Jannetta PJ, Abbasy M, Maroon JC, Ramos FM, Albin MS: Etiology and definitive microsurgical treatment of hemifacial spasm. Operative techniques and results in 47 patients. J Neurosurg 47:321-328, 1977

30. Jannetta PJ, McLaughlin MR, Sekula RF Jr: Microvascular 
decompression, in Jannetta PJ (ed): Trigeminal Neuralgia. New York: Oxford, 2011, pp 192-213

31. Jannetta PJ, Rand RW: Microanatomy of the trigeminal nerve. Anat Rec 154:362, 1966

32. Jannetta PJ, Rand RW: Transtentorial retrogasserian rhizotomy in trigeminal neuralgia by microneurosurgical technique. Bull Los Angeles Neurol Soc 31:93-99, 1966

33. McLaughlin MR, Jannetta PJ, Clyde BL, Subach BR, Comey $\mathrm{CH}$, Resnick DK: Microvascular decompression of cranial nerves: lessons learned after 4400 operations. J Neurosurg 90:1-8, 1999

34. Rand RW: Gardner neurovascular decompression of the trigeminal and facial nerves for tic douloureux and hemifacial spasm. Surg Neurol 16:329-332, 1981

35. Rand RW, Jannetta PJ: Microneurosurgery: application of the binocular surgical microscope in brain tumors, intracranial aneurysms, spinal cord disease, and nerve reconstruction. Clin Neurosurg 15:319-342, 1968

36. Rand RW, Kurze TL: Facial Nerve preservation by posterior fossa transmeatal microdissection in total removal of acoustic tumors. J Neurol Neurosurg Psychiatry 28:311-316, 1965

37. Resnick DK, Jannetta PJ, Bissonnette D, Jho HD, Lanzino G: Microvascular decompression for glossopharyngeal neuralgia. Neurosurgery 36:64-69, 1995

38. Samii M: Foreword: Microvascular decompression, in Jannetta PJ (ed): Trigeminal Neuralgia. New York: Oxford, 2011, pp vii-viii

39. Sekula RF Jr: In Memoriam of Peter J. Jannetta, M.D., D.Sc.: April 5, 1932-April 11, 2016. World Neurosurg 94:584592,2016

40. Shelden CH, Crue BL, Coulter JA: Surgical treatment of trigeminal neuralgia and discussion of compression operation. Postgrad Med 27:595-601, 1960

41. Shelden CH, Pudenz RH, Freshwater DB, Crue BL: Com- pression rather than decompression for trigeminal neuralgia. J Neurosurg 12:123-126, 1955

42. Shelton M: Working in a Very Small Place: The Making of a Neurosurgeon. New York: First Vintage Books Edition, 1990

43. Spiller WG, Frazier CH: The division of the sensory root of the trigeminus for relief of tic douloureux: an experimental, pathologic and clinical study with a preliminary report of one surgically successful case. Phila Med J 8:1039-1049, 1901

44. Stookey B, Ransohoff J: Trigeminal Neuralgia: Its History and Treatment. Springfield, IL: Charles C Thomas, 1959, pp 3-32

45. Taarnhøj P: Decompression of the trigeminal root. J Neurosurg 11:299-305, 1954

\section{Disclosures}

The authors report no conflict of interest concerning the materials or methods used in this study or the findings specified in this paper.

\section{Author Contributions}

Conception and design: both authors. Acquisition of data: both authors. Analysis and interpretation of data: both authors. Drafting the article: both authors. Critically revising the article: both authors. Reviewed submitted version of manuscript: both authors. Approved the final version of the manuscript on behalf of both authors: Kaufmann. Administrative/technical/material support: both authors. Study supervision: both authors.

\section{Correspondence}

Anthony M. Kaufmann: University of Manitoba, Health Sciences Centre, Winnipeg, MB, Canada. akaufmann@hsc.mb.ca. 